\title{
Causative Organism Influences Clinical Profile and Outcome of Infective Endocarditis in Pediatric Patients and Adults With Congenital Heart Disease
}

\author{
Naruhiko Ishiwada, MD; Koichiro Niwa, MD*; Shigeru Tateno, MD*; Masao Yoshinaga, MD**; \\ Masaru Terai, MD; Makoto Nakazawa, $\mathrm{MD}^{\dagger}$; for The Japanese Society of Pediatric \\ Cardiology and Cardiac Surgery Joint Working Groups for Guidelines for Prophylaxis, \\ Diagnosis and Management of Infective Endocarditis \\ in Patients With Congenital Heart Disease
}

\begin{abstract}
Background Studies on microorganisms in a large cohort of patients with congenital heart disease (CHD) and infective endocarditis (IE) are rare. Using a nationwide survey, the relationship between causative microorganisms and clinical profiles in patients with CHD and IE was investigated.

Methods and Results Data from 188 patients with CHD (pediatric patients ( $\mathrm{n}=113$ ), mean age, $6.2 \pm 4.9$ years; adult patients $(\mathrm{n}=75)$, mean age $28.4 \pm 13.4$ years) and IE from 60 institutions were analyzed. Causative microorganisms were Streptococcus species (94:50.0\%), Staphylococcus species (68:36.2\%), Haemophilus species (9:4.8\%), Candida (5:2.7\%), Pseudomonas species $(4: 2.1 \%)$ and other unclassified microorganisms $(8: 4.3 \%)$. Staphylococcal IE was observed significantly higher in perioperative IE (11/16), in cyanotic patients (32/73) and patients younger than 1 year old (11/16). Streptococcal IE was observed significantly higher in acyanotic patients $(64 / 109)$ and patients aged 16 years or older (48/75). Total mortality was 20/188 (10.6\%) and was high for candidial $(2 / 5 ; 40 \%)$ and pseudomonal IE $(2 / 4 ; 50 \%)$. Mortality was highly associated with younger age, especially infants (5/16), and methicillin-resistant staphylococcal IE (6/15).

Conclusions The causative microorganisms are significantly related to the clinical profile and outcome in patients with IE and CHD. These results form the basis for selecting appropriate antibiotics for prevention and management. (Circ J 2005; 69: 1266-1270)
\end{abstract}

Key Words: Children; Congenital heart disease; Infective endocarditis; Microorganisms

$\mathbf{I}$ nfective endocarditis (IE) still has high mortality and is associated with serious complications in patients with congenital heart disease (CHD), despite of advances in antimicrobial treatment! An increased incidence of staphylococcal IE, especially that caused by methicillinresistant Staphylococcus aureus (MRSA) in children with $\mathrm{CHD}$, has been reported? The causative organism and antimicrobial treatment modify the clinical course and prognosis of IE in patients with CHD, but data from a large cohort are scarce. The present study used a large clinical database to determine the relationship between causative organisms and clinical profile/outcome of patients with CHD and IE in order to provide a basis for selecting the appropriate antibiotics for prevention and management of IE in pediatric and adult patients with CHD, as well as establishing proper guidelines for management.

(Received April 6, 2005; revised manuscript received July 4, 2005; accepted July 7, 2005)

Department of Pediatrics, Chiba University Graduate School of Medicine, *Department of Pediatrics, Chiba Cardiovascular Center, Chiba, **Department of Pediatrics, Kagoshima University, Kagoshima and ${ }^{+}$Division of Pediatric Cardiology, Heart Institute of Japan, Tokyo Women's Medical University, Tokyo, Japan

Mailing address: Naruhiko Ishiwada, MD, Department of Pediatrics, Graduate School of Medicine, Chiba University, 1-8-1 Inohana, Chuoku, Chiba-shi, Chiba 260-8670, Japan. E-mail: ishiwada@faculty. chiba-u.jp

\begin{abstract}
Methods
Members of the Japanese Society of Pediatrics Cardiology and Cardiac Surgery in 66 institutions registered 239 pediatric and adult patients with CHD and IE diagnosed by clinical, echocardiographic and microbiologic findings during a 5-year period (1997-2001). The causative organism was identified in 201 patients, CHD was identified in 188 patients, and 13 pediatric patients with no detectable cardiac disease were excluded from the study. The relationships between causative microorganisms and clinical profile/outcome were analyzed in the 188 patients, who comprised 107 males and 81 females, with an age range from 14 days to 63 years (mean, $15.1 \pm 14.3$ years; pediatric patients $(n=$ 113), mean age, $6.2 \pm 4.9$ years and adult patients $(n=75)$, mean age $28.4 \pm 13.4$ ). The data included causative organism, age, diagnosis of CHD, surgical history, source of infection, complications and mortality. There were 73 patients (38.8\%) with cyanotic CHD, which included tetralogy of Fallot (TOF) in 34 (non-repaired: 17), double outlet right ventricle (DORV) in 14 (non-repaired: 9), single ventricle (heterotaxia) in 14 (non-repaired: 13), complete transposition of the great arteries (TGA) in 8 (non-repaired: 1), truncus arteriosus communis in 2 (non-repaired: 0 ), and hypoplastic left heart syndrome in 1 (non-repaired: 1). There were 109 patients (58.0\%) with acyanotic CHD, which included ventricular septal defect (VSD) in 69 (nonrepaired: 57), mitral stenosis/regurgitation in 14 (non-re-
\end{abstract}


paired: 12), aortic stenosis/regurgitation in 8 (non-repaired: 5 ), coarctation of the aorta in 5 (non-repaired: 1), congenitally corrected TGA in 4 (non-repaired: 1 ), atrioventricular septal defect in 3 (non-repaired: 2), atrial septal defect (ASD) in 2 (non-repaired: 0), patent ductus arteriosus in 2 (non-repaired: 2), sinus of Valsalva aneurysm in 1 (non-repaired: 0), and Ebstein's anomaly 1 (non-repaired: 0). Two patients with ASD had an infected ASD patch during the postoperative period.

\section{Age-Related Subgroups}

For analysis of relation between age distribution and causative organisms, we divided the 188 patients into 5 subgroups based on differences in dental development: (1) neonates or infants, (2) 1-5 years, (3) 6-11 years, (4) 12-15 years, and (5) 16 years or older.

\section{Statistical Analysis}

Statistical analysis was performed with the software StatView, SAS Institute Inc (Cary, NC, USA). Numerical data are expressed as mean $\pm \mathrm{SD}$ and either range or number. Discrete variables were analyzed by chi-square test. Continuous data were analyzed across the groups by Kruskal-Wallis test and when significant differences were found $(p<0.05)$, pair-wise comparisons were performed using a two-sample t-test. A p-value $<0.05$ was considered significant. If a survey question was unanswered or the answer was unclear, those data were not counted.

\section{Results}

\section{Causative Microorganisms (Table 1)}

Streptococcus $(n=94: 50.0 \%)$ and Staphylococcus species $(n=68,36.2 \%)$ were the commonest pathogens; 58 of 94 species in streptococcal IE $(63.7 \%)$ were in the mitis group, and 57 of 68 species in staphylococcal IE (83.8\%) was Staphylococcus aureus (S. aureus), with MRSA ac-
Table 1 Causative Microorganism in 188 Cases of Congenital Heart Disease

\begin{tabular}{lc}
\hline \hline Microorganism & No. of cases $(\%)$ \\
\hline Streptococcus spp. & $94(50.0)$ \\
Mitis group & 58 \\
Anginosus group & 3 \\
Pyogenis group & 1 \\
Salivalius group & 1 \\
Mutant group & 1 \\
Unclassified & 30 \\
Staphylococcus spp. & $68(36.2)$ \\
Staphylococcus aureus & 57 \\
Staphylococcus epidermidis & 9 \\
Staphylococcus hominis & 1 \\
Staphylococcus capitis & 1 \\
Haemophilus spp. & $9(4.8)$ \\
Candida spp. & $5(2.7)$ \\
Pseudomonas spp. & $4(2.1)$ \\
Others & $8(4.3)$ \\
Granilicatella spp. & 2 \\
Bacillus spp. & 1 \\
Micrococcus spp. & 1 \\
Moraxella spp. & 1 \\
Gamella spp. & 1 \\
Enterococcus spp. & 1 \\
Anaerobes & 1 \\
\hline
\end{tabular}

counting for $15(26.3 \%)$ of $57 \mathrm{~S}$. aureus strains. The remaining pathogens were Haemophilus $(n=9,4.8 \%)$, Candida $(n=5,2.7 \%)$, and Pseudomonas $(n=4,2.1 \%)$.

\section{Relationship Between Age and Causative Microorganisms (Table 2)}

The patient's age at the onset of IE was available for 188 patients: $16(8.5 \%)$ in the subgroup of neonates or infants (neonates: $n=2$, infants: $n=14), 39(20.7 \%)$ in the subgroup of 1-5 years, $37(19.7 \%)$ in the subgroup of 6-11 years, 21 $(11.2 \%)$ in the subgroup of $12-15$ years, and 75 (39.9\%) in the subgroup of 16 years or older. Streptococcus species

Table 2 Age Groups and Causative Microorganisms

\begin{tabular}{|c|c|c|c|c|c|c|}
\hline \multirow[b]{2}{*}{ Microorganism } & \multicolumn{5}{|c|}{ Age group } & \multirow[b]{2}{*}{ Total } \\
\hline & $\begin{array}{c}\text { Neonates and } \\
\text { infants }\end{array}$ & $1-5$ years & 6-11 years & $12-15$ years & $\geq 16$ years & \\
\hline Streptococcus spp. & 2 & 22 & 16 & 6 & 48 & 94 \\
\hline Staphylococcus spp. & 11 & 7 & 17 & 13 & 20 & 68 \\
\hline Haemophilus spp. & 1 & 5 & 0 & 0 & 3 & 9 \\
\hline Candida spp. & 1 & 1 & 0 & 2 & 1 & 5 \\
\hline Pseudomonas spp. & 1 & 1 & 2 & 0 & 0 & 4 \\
\hline Others & 0 & 3 & 2 & 0 & 3 & 8 \\
\hline Total & 16 & 39 & 37 & 21 & 75 & 188 \\
\hline
\end{tabular}

Table 3 Diagnosis of CHD and Causative Microorganisms

\begin{tabular}{|c|c|c|c|c|c|c|c|c|c|c|c|}
\hline \multirow{3}{*}{ Microorganism } & \multicolumn{10}{|c|}{ Type of $C H D$} & \multirow{3}{*}{ Total } \\
\hline & \multicolumn{5}{|c|}{ Cyanotic CHD $(n=73)$} & \multicolumn{4}{|c|}{ Acyanotic CHD $(n=109)$} & \multirow{2}{*}{ Unknown } & \\
\hline & TOF & $D O R V$ & Heterotaxia & $T G A$ & Other & $V S D$ & $M S / M R$ & $A S / A R$ & Other & & \\
\hline Streptococcus spp. & $12(8)$ & $6(4)$ & $7(7)$ & $3(0)$ & $0(0)$ & $43(38)$ & $6(5)$ & $5(3)$ & $10(4)$ & 2 & 94 \\
\hline Staphylococcus spp. & $16(5)$ & $6(5)$ & $3(3)$ & $4(0)$ & $3(1)$ & $20(16)$ & $7(7)$ & $1(1)$ & $5(1)$ & 3 & 68 \\
\hline Haemophilus spp. & $3(3)$ & $1(0)$ & $2(1)$ & $1(1)$ & $0(0)$ & $1(1)$ & $0(0)$ & $0(0)$ & $1(1)$ & 0 & 9 \\
\hline Candida spp. & $1(0)$ & $1(0)$ & $0(0)$ & $0(0)$ & $0(0)$ & $0(0)$ & $0(0)$ & $1(0)$ & $1(0)$ & 1 & 5 \\
\hline Pseudomonas spp. & $1(0)$ & $0(0)$ & $1(1)$ & $0(0)$ & $0(0)$ & $0(0)$ & $1(0)$ & $0(0)$ & $1(0)$ & 0 & 4 \\
\hline Others & $1(1)$ & $0(0)$ & $1(1)$ & $0(0)$ & $0(0)$ & $5(2)$ & $0(0)$ & $1(1)$ & $0(0)$ & 0 & 8 \\
\hline Total & $34(17)$ & $14(9)$ & $14(13)$ & $8(1)$ & $3(1)$ & $69(57)$ & $14(12)$ & $8(5)$ & $18(6)$ & 6 & 188 \\
\hline
\end{tabular}

CHD, congenital heart disease; TOF, tetralogy of Fallot; DORV, double outlet right ventricule; TGA, transposition of the great arteries; VSD, ventricular septal defect; MS/MR, mitral valve stenosis/regurgitation; AS/AR, aortic valve stenosis/regurgitation. Results in parentheses are cases of previous cardiac surgery. 
Table 4 Source of Infection and Causative Microorganisms

\begin{tabular}{|c|c|c|c|c|c|c|c|c|c|c|}
\hline \multirow[b]{2}{*}{ Microorganism } & \multicolumn{9}{|c|}{ Predisposing condition } & \multirow[b]{2}{*}{ Total } \\
\hline & $\begin{array}{c}\text { Dental } \\
\text { procedure }\end{array}$ & $\begin{array}{l}\text { Cardiac } \\
\text { surgery }\end{array}$ & Pneumonia & $\begin{array}{c}\text { Otolaryngeal } \\
\text { procedure }\end{array}$ & $\begin{array}{c}\text { Unexpected } \\
\text { trauma }\end{array}$ & $\begin{array}{c}\text { Atopic } \\
\text { dermatitis }\end{array}$ & URTI & Other & Unknown & \\
\hline Streptococcus spp. & 17 & 1 & 4 & 2 & 1 & 0 & 1 & 2 & 66 & 94 \\
\hline Staphylococcus spp. & 3 & 7 & 1 & 1 & 1 & 2 & 1 & 5 & 47 & 68 \\
\hline Haemophilus spp. & 0 & 0 & 0 & 1 & 1 & 0 & 0 & 1 & 6 & 9 \\
\hline Candida spp. & 0 & 3 & 0 & 0 & 0 & 0 & 0 & 1 & 1 & 5 \\
\hline Pseudomonas spp. & 0 & 0 & 0 & 0 & 0 & 0 & 0 & 0 & 4 & 4 \\
\hline Others & 3 & 0 & 0 & 0 & 0 & 0 & 0 & 0 & 5 & 8 \\
\hline Total & 23 & 11 & 5 & 4 & 3 & 2 & 2 & 9 & 129 & 188 \\
\hline
\end{tabular}

URTI, upper respiratory tract infection.

Table 5 History of Cardiac Surgery and Causative Microorganisms

\begin{tabular}{lccccc}
\hline \hline \multirow{2}{*}{ Microorganism } & \multicolumn{4}{c}{ Surgical status } & \multirow{2}{*}{ Total } \\
\cline { 2 - 4 } & Unrepaired & Palliative & Post-repair & Unknown n & \\
\hline Streptococcus spp. & 52 & $17(1)$ & $23(0)$ & 2 & $94(1)$ \\
Staphylococcus spp. & 27 & $12(2)$ & $28(9)$ & 1 & $68(11)$ \\
Haemophilus spp. & 1 & $6(0)$ & $2(0)$ & 0 & $9(0)$ \\
Candida spp. & 1 & $0(0)$ & $4(3)$ & 0 & $5(3)$ \\
Pseudomonas spp. & 0 & $1(0)$ & $3(0)$ & 0 & $4(0)$ \\
Others & 3 & $2(1)$ & $3(0)$ & 0 & $8(1)$ \\
Total & 84 & $38(4)$ & $63(12)$ & 3 & $188(16)$ \\
\hline
\end{tabular}

Results in parenthesis are no. of cases of perioperative infection.

Table 6 Site of Infection and Causative Microorganisms

\begin{tabular}{|c|c|c|c|c|c|c|c|c|c|c|c|c|}
\hline \multirow[b]{2}{*}{ Microorganism } & \multicolumn{11}{|c|}{ Site of infection } & \multirow[b]{2}{*}{ Tota } \\
\hline & $T V$ & $M V$ & $A V$ & $P V$ & $\begin{array}{c}A V+ \\
M V\end{array}$ & $\begin{array}{c}P V+ \\
T V\end{array}$ & $\begin{array}{c}A V+M V \\
\quad+T V\end{array}$ & Conduit & $\begin{array}{c}\text { Artificial } \\
\text { patch }\end{array}$ & Othter & Unknown & \\
\hline Streptococcus spp. & $16(1)$ & $15(0)$ & $6(0)$ & $4(1)$ & $3(0)$ & 0 & $1(0)$ & 1 & 1 & 13 & 34 & 94 \\
\hline Staphylococcus spp. & $9(0)$ & $9(0)$ & $5(0)$ & $1(0)$ & 0 & $1(0)$ & 0 & 4 & 6 & 15 & 18 & 68 \\
\hline Haemophilus spp. & $1(0)$ & 0 & 0 & 0 & 0 & 0 & 0 & 0 & 1 & 1 & 6 & 9 \\
\hline Candida spp. & $1(1)$ & $1(0)$ & 0 & $1(0)$ & 0 & 0 & 0 & 2 & 0 & 0 & 0 & 5 \\
\hline Pseudomona spp. & $1(0)$ & 0 & 0 & 0 & 0 & 0 & 0 & 1 & 0 & 1 & 1 & 4 \\
\hline Others & $1(0)$ & $1(0)$ & $2(0)$ & 0 & 0 & 0 & 0 & 0 & 1 & 1 & 2 & 8 \\
\hline Total & $29(2)$ & $26(0)$ & $13(0)$ & $6(1)$ & $3(0)$ & $1(0)$ & $1(0)$ & 8 & 9 & 31 & 61 & 188 \\
\hline
\end{tabular}

$T V$, tricuspid valve; $M V$, mitral valve; $A V$, aortic valve; $P V$, pulmonary valve. Results in parentheses are no. of infected prosthetic valves.

were more frequent than Staphylococcus species (48/94 vs $20 / 68, p<0.05$ ) in patients aged 16 years or older, whereas in the neonate and infant subgroup, Staphyloccus species were more frequent $(11 / 68$ vs $2 / 94, \mathrm{p}<0.05)$. Pseudomonas species were observed only in children under 11 years of age.

\section{Relationship Between Diagnosis of CHD and Causative Microorganisms (Table 3)}

The main causes of cyanotic CHD were TOF, DORV and heterotaxia, whereas VSD was the main cause of acyanotic CHD. In 13 of $14(92.9 \%)$ cyanotic patients with heterotaxia, and in 57 of $69(82.6 \%)$ acyanotic patients with VSD, IE developed in the case of non-repair or palliative surgery. In patients with cyanotic CHD, Staphylococcus species $(32 / 68,47.1 \%)$ were more frequent than Streptococcus species $(28 / 94,29.8 \%)(\mathrm{p}<0.05)$, whereas in patients with acyanotic CHD, Streptococcus species (64/94, $68.1 \%)$ were more frequent $(33 / 68,48.5 \%)(\mathrm{p}<0.05)$.

\section{Source of Infection (Table 4)}

The likely source of infection was identified in 59 patients $(31.4 \%)$. The preceding factor of IE was determined in 28 of 94 patients with streptococcal IE (dental procedure
$(17 / 28,60.7 \%)$; pneumonia $(4 / 28,14.3 \%))$, and in 21 of 68 of patients with staphylococcal IE (cardiac surgery (7/21, $33.3 \%)$; dental procedure $(3 / 21,14.3 \%)$; atopic dermatitis $(2 / 21,9.5 \%))$.

Cardiac Surgery and Causative Microorganisms (Table 5)

Streptococcus species were isolated in 52 of 84 patients $(61.9 \%)$ without previous cardiac surgery and Staphylococcus species in 27 (32.1\%). IE developed in 101 patients with previous cardiac surgery, including 38 with palliative surgery, of whom $16(15.8 \%)$ developed IE perioperatively.

Site of Infection and Causative Microorganisms (Table 6)

Atrioventricular valves were the most commonly affected sites. The tricuspid valve was affected in 31 patients $(16.5 \%)$ and the mitral valve in 30 patients (16.0\%). In 5 of these 61 patients, 2 or 3 valves were infected, and 3 of 85 infected valves $(3.5 \%)$ from 79 patients were prosthetic valves. The incidence of infected artificial materials such as conduits and patches was high $(10 / 68,14.7 \%)$ in staphylococcal IE compared with streptococcal IE $(2 / 94,2.1 \%)$ $(\mathrm{p}<0.05)$. 
Table 7 Complications and Causative Microorganisms

\begin{tabular}{|c|c|c|c|c|c|c|c|c|}
\hline & Vegetation & $\begin{array}{c}\text { Valvular } \\
\text { regurgitation }\end{array}$ & $\begin{array}{l}\text { Cardiac } \\
\text { failure }\end{array}$ & Arrhythmias & $\begin{array}{c}\text { CNS } \\
\text { embolism }\end{array}$ & $\begin{array}{c}\text { Other } \\
\text { embolism }\end{array}$ & Abscess & Aneurysm \\
\hline Streptococcus spp. & 54 & 32 & 22 & 6 & 9 & 8 & 5 & 2 \\
\hline Staphylococcus spp. & 41 & 19 & 12 & 4 & 4 & 7 & 4 & 0 \\
\hline Haemophilus spp. & 1 & 3 & 1 & 0 & 0 & 0 & 0 & 1 \\
\hline Candida spp. & 5 & 1 & 1 & 0 & 0 & 1 & 0 & 0 \\
\hline Pseudomona spp. & 3 & 1 & 0 & 0 & 0 & 1 & 0 & 0 \\
\hline Others & 5 & 2 & 2 & 0 & 0 & 0 & 0 & 0 \\
\hline Total & 109 & 58 & 38 & $\begin{array}{c}10 \\
5.20\end{array}$ & 13 & 17 & $\begin{array}{l}9 \\
907\end{array}$ & 3 \\
\hline
\end{tabular}

CNS, central nervous system.

Table 8 Cases of Fatal IE

\begin{tabular}{|c|c|c|c|c|c|}
\hline $\begin{array}{c}\text { Case } \\
\text { no. }\end{array}$ & Age & Diagnosis of $C H D$ & $\begin{array}{c}\text { Cardiac surgical } \\
\text { status }\end{array}$ & $\begin{array}{c}\text { Antibiotis administered } \\
\text { before diagnosis of IE }\end{array}$ & Microorganism \\
\hline 1 & $1 Y$ & TOF & Palliative & + & Streptococcus mitis \\
\hline 2 & $9 Y$ & $A S / A R$ & No & + & Streptococcus mitis \\
\hline 3 & $22 Y$ & Others & No & - & Streptococcus mitis \\
\hline 4 & $3 Y$ & $D O R V$ & Palliative & - & Streptococcus oralis \\
\hline 5 & $0 Y 7 M$ & Heterotaxia & Palliative & - & Streptococcus pneumoniae \\
\hline 6 & $9 Y$ & TOF & No & + & Staphylococcus aureus \\
\hline 7 & $10 Y$ & $V S D$ & No & + & Staphylococcus aureus \\
\hline 8 & $13 Y$ & DORV & Post-repair & + & Staphylococcus aureus \\
\hline 9 & $21 Y$ & Unknown & No & - & Staphylococcus aureus \\
\hline 10 & $23 Y$ & $V S D$ & Post-repair & + & Staphylococcus aureus \\
\hline 11 & $0 Y 2 M$ & $E C D$ & Post-repair & + & Staphylococcus aureus (MRSA) \\
\hline 12 & $0 Y 2 M$ & $T G A$ & Post-repair & + & Staphylococcus aureus (MRSA) \\
\hline 13 & $0 Y 4 M$ & $V S D$ & Post-repair & - & Staphylococcus aureus (MRSA) \\
\hline 14 & $12 Y$ & DORV & Post-repair & + & Staphylococcus aureus (MRSA) \\
\hline 15 & $21 Y$ & TOF & Palliative & + & Staphylococcus aureus (MRSA) \\
\hline 16 & $25 Y$ & VSD & No & - & Staphylococcus aureus (MRSA) \\
\hline 17 & OY10M & $M S / M R$ & Post-repair & + & Pseudomonas aeruginosa \\
\hline 18 & $1 Y$ & Heterotaxia & Palliative & + & Pseudomonas aeruginosa \\
\hline 19 & $13 Y$ & $D O R V$ & Post-repair & + & Candida spp. \\
\hline 20 & $25 Y$ & TOF & Palliative & + & Candida spp. \\
\hline
\end{tabular}

IE, infective endocarditis; CHD, congenital heart disease; $Y$, years; TOF, tetralogy of Fallot; AS/AR, aortic valve stenosis/regurgitation; $M$, months; DORV, double-outlet right ventricle; VSD, ventricular septal defect; ECD, endocardial cushion defect; TGA, complete transposition of the great arteries; $M S / M R$, mitral valve stenosis/regurgitation.

Complications and Causative Microorganisms (Table 7)

Complications were common $(126 / 188=67.0 \%)$ and there was no significant difference in the incidence of complications among the different causative species. The incidence of vegetations was very low $(1 / 9,11.1 \%)$ with IE caused by Haemophilus species compared with the other species $(\mathrm{p}<0.05)$.

\section{Fatal IE (Table 8)}

Twenty patients $(10.6 \%)$ died of IE at a mean age of 10.5 years ( 2 months to 25 years). Mortality was highest in patients less than 1 year of age $(5 / 16,31.3 \%)$ compared with the other subgroups; $7.7 \%(3 / 39)$ in $1-5$ years, $8.1 \%$ $(3 / 37)$ in $6-11$ years, $14.3 \%(3 / 21)$ in $12-15$ years and $8.0 \%(6 / 75)$ in 16 years or older. Fourteen deaths were in patients $(70.0 \%)$ who had undergone cardiac surgery, 11 of whom were given prophylactic antibiotics before the onset of IE. S. aureus was isolated from 11 of the 20 dead patients $(55.0 \%)$ including 7 with MRSA, whereas Streptococcus mitis was the causative pathogen only in 3 of the fatal cases $(15.0 \%)$. The overall mortality was higher for S. aureus $(11 / 57,19.3 \%)$ than for the Streptococcus species $(5 / 94,5.3 \%, \mathrm{p}<0.05)$. Although Candida and Pseudomonas species were rare, the mortality was high for both: Candida $(2 / 5,40.0 \%)$ and Pseudomonas $(2 / 4,50.0 \%)$. Candida species were primarily isolated from fatal cases with long- term intravenous antibiotic treatment.

\section{Discussion}

The causative microorganism significantly influences the clinical profile and course in CHD patients with IE. The present results will help in matching the causative organism with the clinical manifestation, and therefore in the selection of the correct antibiotics for prevention and management.

\section{Microorganisms}

In this study, Streptococcus and Staphylococcus species were the most commonly isolated of the causative organisms for IE, and the Streptococcus mitis group was the most frequent. Nakatani et al in Japan recently described the annual trend of IE in 817 adults with various cardiovascular diseases, including 9.1\% who had CHD, and they isolated 697 microorganisms (85\%), with 50\% Streptococcus species and $32 \%$ Staphylococcus species? In a UK survey of IE in adults with cardiovascular disease, including 27\% with CHD, conducted between 1987 and 1996, Streptococcus species comprised $49 \%$ and Staphylococcus species comprised $26 \%$ ? In contrast, a US study reported that Staphylococcus species caused $50 \%$ of all episodes of IE in pediatric patients, followed by Streptococcus species 
in $22 \%$ ! The results of the present study are similar to those in previous reports from Japan and the UK studies, but different from the US study, and the discrepancy may be related to patient age, type of CHD and type of preventive measures. The incidence of staphylococcal IE was higher in patients with cyanotic CHD than in those with acyanotic CHD. In the US study, $51 \%$ of the CHD patients were cyanotic CHD vs $39 \%$ in our study. There was a significant difference between staphylococcal IE and streptococcal IE in mean age: 12.8 and 17.6 years, respectively. In patients under 1 year of age, the prevalence of staphylococcal IE was significantly higher than that of streptococcal IE (16.2\% vs $2.1 \%$ ). Furthermore, $81.8 \%$ of the S. aureus strains cultured from these patients were MRSA.

\section{Predisposing Factors for IE}

In this study, the leading predisposing risk factor was dental procedures. The American Heart Association recommends antibiotic prophylaxis for dental procedures in patients with most types of CHD, excluding simple ASD and repaired simple CHD without postoperative residua beyond 6 months postoperatively? In our study, $53.7 \%$ of patients with CHD had undergone cardiac surgery, and perioperative IE was observed in $8.5 \%$, an incidence similar to previous reports, 10 Cardiac surgery was the second most frequent predisposing risk factor, and Staphylococcus species were the major pathogen. Atopic dermatitis was a frequent predisposing risk factor for staphylococcal IE. Although there are only a few case reports of IE associated with atopic dermatitis, 1,12 the incidence of atopic dermatitis in Japan is rapidly increasing, a warning that prophylactic measures should be taken to prevent IE.

\section{Infected Sites}

The infected valve differed markedly between IE patients with CHD and without CHD. The aortic valve was the most commonly affected site in IE patients without $\mathrm{CHD}$, whereas the tricuspid and mitral valves were the most common affected sites in those with CHD. The incidence of prosthetic valve IE in patients with CHD was lower than in the adult cohort, ${ }^{13}$ and infection of artificial materials, such as conduits and patches, mainly occurred with staphylococcal IE.

\section{Morbidity and Mortality}

Despite remarkable developments and improvements in the treatment of IE, morbidity and mortality remain high, 14,15 as high as $10.0 \%$ in the present study. IE caused by MRSA had the highest mortality, followed by Candida and Pseudomonas, even though the latter are rare pathogens. These organisms are typically hospital-acquired, nosocomial pathogens that have been increasingly observed in patients with IE since the 1980s. S. aureus has been recognized as an important pathogen since the 1970s, and recently MRSA and coagulase-negative staphylococci have increased in prevalence!3,16 There has also been an increased incidence of fungal endocarditis,${ }^{17}$ reflecting the longer duration of broad-spectrum antimicrobial therapy in seriously ill patients. Novel therapies against nosocomial pathogens are needed to improve patient outcome.

\section{Conclusions}

The causative microorganism is significantly related to the clinical profile and outcome of IE. Staphylococcal IE is frequent in perioperative patients less than 1 year of age, in patients with cyanotic CHD, and in older patients with atopic dermatitis, whereas streptococcal IE is frequent in patients aged 16 years or more, with acyanotic CHD and without previous cardiac surgery.

\section{Acknowledgments}

This work was supported in part by the fund from the Japanese Society of Pediatric Cardiology and Cardiac Surgery Joint Working Groups for Guidelines for Prophylaxis, Diagnosis and Management of Infective Endocarditis in Patients with Congenital Heart Disease.

We gratefully acknowledge the assistance of members of the Japanese Society of Pediatric Cardiology and Cardiac Surgery Joint Working Groups for Guidelines for Prophylaxis, Diagnosis and Management of Infective Endocarditis in Patients with Congenital Heart Disease; Shigeyuki Echigo, MD, Taku Fujiwara, DDS, Kazumi Kubota, DDS, Tomiaki Murakami, MD, Fukiko Ichida, MD, Kunitaka Joo, MD, Noriyuki Haneda, MD, Takashi Higaki, MD, Hiroshi Suzuki, MD, Hideki Uemura, MD and Hiroyuki Fukushima, MD in the collecting data and in particular, the assistance of Atsuko Niwa, MD, in preparing the manuscript and analyzing the data. We gratefully acknowledge Joseph K Perloff, MD, for assessing the manuscript.

\section{References}

1. Saiman L, Prince A, Gersony WM. Pediatric infective endocarditis in the modern era. J Pediatr 1993; 122: 847-853.

2. Abraham J, Mansour C, Veledar E, Khan B, Lerakis S. Staphylococcus aureus bacteremia and endocarditis: The Grady Memorial Hospital experience with methicillin-sensitive S. aureus and methicillinresistant S aureus bacteremia. Am Heart J 2004; 147: 536-539.

3. Hoen B, Selton-Suty C, Lacassin F, Etienne J, Briancon S, Leport C, et al. Infective endocarditis in patients with negative blood cultures: Analysis of 88 cases from a one-year nationwide survey in France. Clin Infect Dis 1995; 20: 501-506.

4. Goldenberger D, Kunzli A, Vogt P, Zbinden R, Altwegg M. Molecular diagnosis of bacterial endocarditis by broad-range PCR amplification and direct sequencing. J Clin Microbiol 1997; 35: 2733-2739.

5. Nakatani S, Mitsutake K, Hozumi T, Yoshikawa J, Akiyama M, Yoshida K, et al. Current characteristics of infective endocarditis in Japan: An analysis of 848 cases in 2000 and 2001. Circ J 2003; 67: 901-905.

6. Dyson C, Barnes RA, Harrison GAJ. Infective endocarditis: An epidemiological review of 128 episodes. J Infect 1999; 38: 87-93.

7. Dajani AS, Taubert KA, Wilson W, Bolger AF, Bayer A, Ferrieri P, et al. Prevention of bacterial endocarditis: Recommendation by the American Heart Association. JAMA 1997; 96: 358-366.

8. Niwa K, Nakazawa M, Miyatake K, Tateno S, Yoshinaga M. Survey of prophylaxis and management of infective endocarditis in patients with congenital heart disease: Japanese nationwide survey. Circ $J$ 2003; 67: 585-591.

9. Cetta F, Warnes CA. Adults with congenital heart disease: Patient knowledge of endocarditis prophylaxis. Mayo Clin Proc 1995; 70: 50-54.

10. Awadallah SM, Kavey REW, Byrum CJ, Smith FC, Kveselis DA, Blackman MS. The changing pattern of infective endocarditis in childhood. Am J Cardiol 1991; 68: 90-94.

11. Kobayashi H, Sugiuchi R, Tabata N, Ninomiya M, Oumi M, Sadahiro $\mathrm{M}$, et al. Acute infectious endocarditis with Janeway lesions in a patient with atopic dermatitis. Eur J Dermatol 1999; 9: 239-240.

12. Grabczynska SA, Cerio R. Infective endocarditis associated with atopic eczema. Br J Dermatol 1999; 140: 1193-1194.

13. Mylonakis E, Calderwood SB. Infective endocarditis in adults. $N$ Engl J Med 2001; 345: 1318-1330.

14. Netzer RO, Zollinger E, Seiler C, Cerny A. Infective endocarditis: Clinical spectrum, presentation and outcome: An analysis of 212 cases 1980-1995. Heart 2000; 84: 25-30.

15. Nissen H, Nielsen PF, Frederiksen M, Helleberg C, Nielsen JS. Native valve infective endocarditis in the general population: A 10-year survey of the clinical picture during the 1980s. Eur Heart J 1992; 13: $872-877$.

16. Van Hare GF, Ben-Shachar G, Liebman J, Boxerbaum B, Riemenschneider TA. Infective endocarditis in infants and children during the past 10 years: A decade of change. Am Heart J 1984; 107: $1235-1240$.

17. Pierrotti LC, Baddour LM. Fungal endocarditis, 1995-2000. Chest 2002; 122: 302-310. 